\title{
A glycine ruthenium trithiacyclononane complex and its molecular encapsulation using cyclodextrins $\dagger$
}

\author{
Joana Marques, ${ }^{a}$ Teresa M. Santos, ${ }^{a}$ Maria Paula Marques ${ }^{b}$ and Susana S. Braga ${ }^{* a}$ \\ Received 3rd August 2009, Accepted 1st September 2009 \\ First published as an Advance Article on the web 28th September 2009 \\ DOI: 10.1039/b915839a
}

The complex $\mathrm{Ru}\left([9] \mathrm{aneS} \mathrm{S}_{3}\right)(\mathrm{gly}) \mathrm{Cl}$ (gly = glycine) was obtained from the reaction of the precursor $\mathrm{Ru}\left([9] \mathrm{aneS}_{3}\right) \mathrm{dmsoCl}_{2}$ with glycine and encapsulated into native $\beta-\mathrm{CD}$, a hydroxypropylated derivative HP $\beta C D$, and the methylated cyclodextrins TRIMEB and CRYSMEB. All four inclusion compounds were obtained with a 1:1 host:guest stoichiometry and characterised in the solid-state by powder X-ray diffraction, thermogravimetric analysis (TGA), and ${ }^{13} \mathrm{C}\left\{{ }^{1} \mathrm{H}\right\} \mathrm{CP} / \mathrm{MAS}$ NMR and FTIR spectroscopies. The cytostatic and antiproliferative activity of the complex $\mathrm{Ru}\left([9] \mathrm{aneS} \mathrm{S}_{3}\right)(\mathrm{gly}) \mathrm{Cl}$ and its four $\mathrm{CD}$ inclusion compounds was tested on the human osteosarcoma MG-63 cell line and the results compared to the inhibitory effect exerted by the pure cyclodextrins.

\section{Introduction}

The interest on developing new metal antitumour compounds has grown steadily ${ }^{1}$ since the discovery of the anticancer activity of cisplatin. ${ }^{2}$ Metal complexes present unique properties due to their wide spectrum of coordination numbers and geometries ${ }^{3,4}$ and various redox states accessible. ${ }^{4}$ Ruthenium complexes, in particular, are usually presented in the $\mathrm{Ru}(\mathrm{III})$ and $\mathrm{Ru}(\mathrm{II})$ oxidation states; Ru(III) complexes act as prodrugs undergoing in vivo activation to the $\mathrm{Ru}(\mathrm{II})$ state. Recent developments of ruthenium antitumour complexes include, thus, $\mathrm{Ru}(\mathrm{II}) \eta^{6}$-arene complexes, or analogues ${ }^{5}$ bearing the neutral face-capping ligand 1,4,7-trithiacyclononane ([9]ane $\mathrm{S}_{3}$ ), of which the first example was $\left[\mathrm{Ru}\left([9] \mathrm{aneS}_{3}\right)(\mathrm{en}) \mathrm{Cl}\right]\left[\mathrm{CF}_{3} \mathrm{SO}_{3}\right]$ (en = ethylenediamine), exhibiting activity against the mouse adenocarcinoma cancer cell line TS/A. ${ }^{6}$ The cytotoxic activity of $\mathrm{Ru}[9] \mathrm{aneS}_{3}$ complexes can be further enhanced and broadened by using a combination of different strategies, listed as follows:

(i) Incorporation of planar heteroaromatic amine ligands with DNA-intercalating properties, as in $\left[\mathrm{Ru}\left([9] \mathrm{aneS}_{3}\right) \mathrm{dppzCl}\right] \mathrm{Cl}$ (dppz $=$ dipyrido[3,2a: $2^{\prime}, 3^{\prime}$ c]phenazine $) .^{7}$

(ii) Molecular encapsulation with suitable carriers as cyclodextrins (CDs), cyclic water soluble oligosaccharides used to protect the guests from oxidation, UV degradation or inactivation by biomolecules. ${ }^{8}$ In the past years, our group has used CDs to form inclusion compounds ${ }^{9}$ with organic ${ }^{10}$ and metalloorganic species and reported an increased antitumoural action of $\mathrm{Cp}_{2} \mathrm{MoCl}_{2}{ }^{11}$ and $\left[\mathrm{CpMo}\left(\mathrm{H}_{2}\right.\right.$ biim $\left.)\left(\mathrm{CO}_{2}\right)\right]\left[\mathrm{BF}_{4}\right]^{12}$ in particular by methylated CDs (TRIMEB for the first and DIMEB for the latter), as well as improved antimicrobial action of the complex $\left[\mathrm{Ru}\left([9] \mathrm{aneS}_{3}\right)\right.$ phenCl] $\mathrm{Cl}$ against several bacterial strains ${ }^{13}(\mathrm{Cp}=$ $\eta^{5} \mathrm{C}_{5} \mathrm{H}_{5}$, biim $=$ bisimidazole, phen $=1,10$-phenanthroline $)$.

${ }^{a}$ Department of Chemistry, CICECO, University of Aveiro, 3810-193, Aveiro, Portugal.E-mail: sbraga@ua.pt; Fax:+351-234401470

${ }^{b}$ Science and Technology Faculty, Molecular Physical Chemistry Research Group, Department of Chemistry, University of Coimbra, Apt. 3126, 3001401, Coimbra, Portugal

$\dagger$ Work first presented at the 10th FIGIPAS Meeting in Inorganic Chemistry, Palermo, July 1-4, 2009. (iii) Incorporation of simple biomolecules, as $\alpha$-amino acids, to obtain bio-inorganic complexes with affinity to DNA. ${ }^{14}$ This strategy, though remaining unexplored for ruthenium antitumour complexes, has been extensively tested for platinum complexes, most likely in search for cisplatin substitutes, resulting in the development of a $\mathrm{Pt}(\mathrm{L}-\mathrm{lysine}) \mathrm{Cl}_{2}$ complex with activity 100fold higher than cisplatin on HeLa cells, ${ }^{15}$ and of a Pt[2- $\left(2^{\prime}-\right.$ thienyl)pyridine](glycine) with strong antiproliferative activity on human carcinoma SF268 and MCF7 lines accompanied by low toxicity on healthy cells. ${ }^{16}$

In the present work, we prepare the first $\left\{\mathrm{Ru}\left([9] \mathrm{aneS}_{3}\right)(\right.$ amino acid) $\}$ complex and combine this biomimicry strategy with the carrier effect granted by encapsulation into different cyclodextrins, aiming to obtain a compound suitable for osteosarcoma chemotherapy. Osteoblasts express glutamate receptors, in which glycine acts as a co-agonist, ${ }^{17}$ and have thus been proposed as suitable targets for osteosarcoma chemotherapy by using compounds able to bind and block the receptors, inhibiting normal osteoblast functionality. ${ }^{18}$ We therefore chose to incorporate the amino acid glycine, designing the ruthenium complex for glutamate receptor specific binding and subsequent blockage by the Ru-trithiacyclononane cap.

\section{Results and discussion}

\section{Synthesis of the $\mathrm{Ru}[9] \mathrm{aneS}_{3}$ glycinate complex (1)}

The precursor $\mathrm{Ru}\left([9] \mathrm{aneS}_{3}\right) \mathrm{dmsoCl}_{2}$ was refluxed in ethanol for $24 \mathrm{~h}$ with a slight excess $(10 \%)$ of glycine and sodium bicarbonate. Decanting and drying of the resulting brown solution yielded $\mathrm{Ru}\left([9] \mathrm{aneS}_{3}\right)(\mathrm{gly}) \mathrm{Cl}(\mathbf{1})$. This procedure allows one to prepare $\mathbf{1}$ in a simple and reproducible way. The purity of the products was confirmed by elemental analysis, with the ruthenium content being determined by ICP-OES spectroscopy. Glycinate coordination in $\mathbf{1}$, as observed for most complexes of the $\alpha$-amino acids and metal ions, is expected to follow from the usual bidentate N,O-donor binding mode. ${ }^{19}$ Recently, this mode was verified and fully described by single-crystal diffraction for the $\mathrm{Ru}$ (bipyridine) ${ }_{2}$ tyrosinate complex. ${ }^{20}$ The glycine 
coordination mode on the complex 1 was first investigated by FT-IR spectroscopy. Observations focused on changes on the carboxylate anti-symmetric and symmetric stretching modes, the first represented by a broad band centred at $1613 \mathrm{~cm}^{-1}$ (blueshifted when compared to $1605 \mathrm{~cm}^{-1}$ for pure glycine) $)^{21}$ and the latter appearing at $1395 \mathrm{~cm}^{-1}$ (redshifted in comparison to pure glycine, with a band maximum at $1413 \mathrm{~cm}^{-1}$ ). These shifts are associated with the coordination of the carboxylato groups. ${ }^{22}$ Formation of the $\mathrm{Ru}-\mathrm{N}$ bond ${ }^{23}$ was confirmed by observation of a series of weak modes at 338,331 and $324 \mathrm{~cm}^{-1}$.

\section{Inclusion of complex 1 into cyclodextrins}

All the inclusion compounds were prepared starting with an initial $\mathrm{CD} /$ guest molar ratio of 1:1. The good aqueous solubility of the guest 1 allowed the encapsulation procedures to be performed by co-dissolution in water, with the help of ethanol as co-solvent only required for $\beta$-CD. Solvent removal led to the isolation of the adducts $\mathbf{2}$ to $\mathbf{5}$ as brown solids, and their elemental analysis confirmed that the final host:guest molar ratios were 1:1.

$\mathrm{X}$-ray powder diffraction studies were performed on the solids to investigate the formation of true inclusion compounds of cyclodextrins, with base on the empirical evidence that their powder XRD patterns should be clearly distinct from those obtained by the superimposition of the diffractograms of each individual component. Fig. 1 shows the patterns for the complex $\mathbf{1}$, $\beta$-CD, CRYSMEB, and their corresponding inclusion compounds ( 2 and $\mathbf{5}$, respectively). The diffraction patterns for $\mathbf{1}$ encapsulated in permethylated cyclodextrin, TRIMEB, revealed an amorphous phase. HP $\beta C D$, with an average degree of substitution of three hydroxypropyl groups per CD molecule, is also amorphous and renders amorphous adducts, thus the patterns for compounds $\mathbf{3}$ and $\mathbf{4}$ are not presented in Fig. 1.

The diffractogram for $\beta$-CD· $\mathrm{Ru}\left([9] \mathrm{aneS}_{3}\right)(\mathrm{gly}) \mathrm{Cl}(2)$, in spite of its low crystallinity, allowed us to observe that there are no reflections ascribed to $\beta-C D$ nor the pure guest, which is an early indication of the formation of a true inclusion compound. Furthermore, the most intense reflections (at 5.9, 6.9, 11.8, 12.8, $14.8,15.7,18.2$ and $21.0^{\circ}$ ) can be associated with the two series described by $\mathrm{Caira}^{24}$ for inclusion compounds featuring head-tohead dimers of $\beta-C D$ stacked in infinite channels. We can therefore infer that there is a similar host packing in the adduct $\mathbf{2}$.

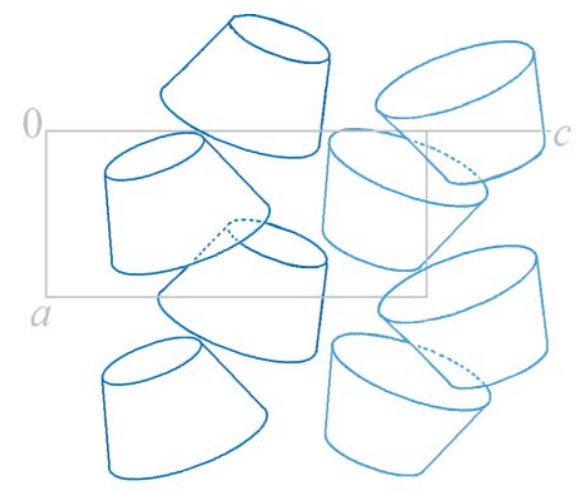

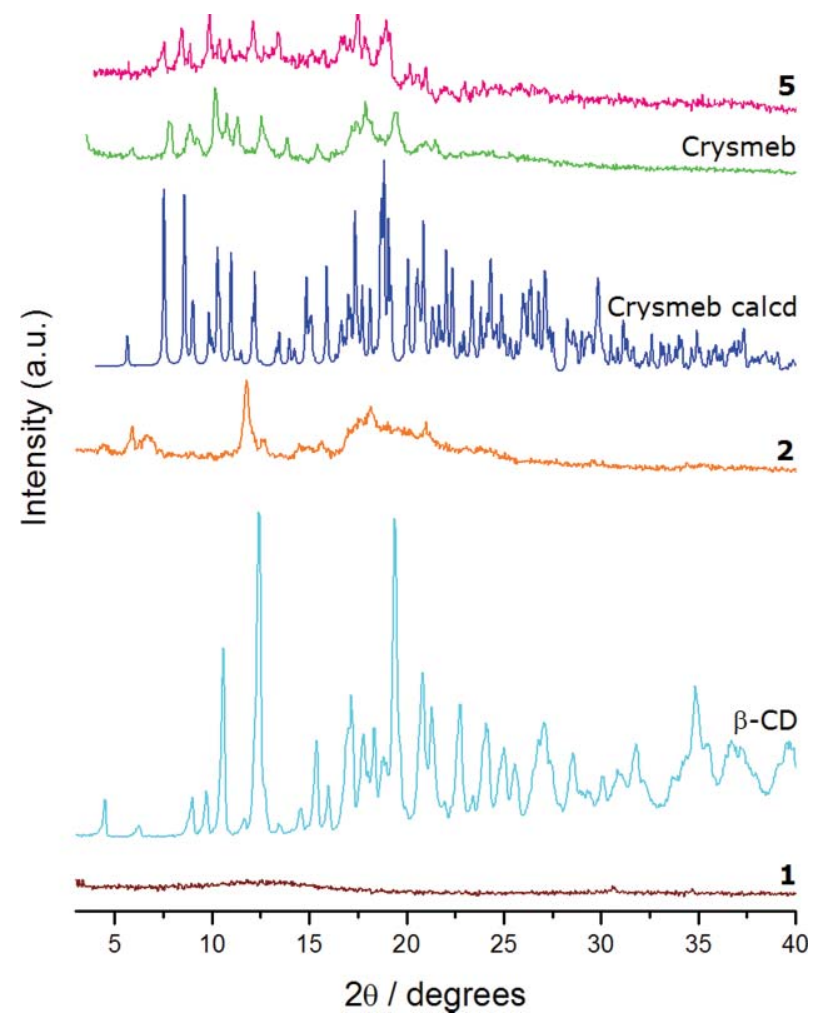

Fig. $1 \mathrm{X}$-ray diffraction patterns for the guest 1 (brown), $\beta$-CD (cyan), their corresponding adduct 2 (orange), a theoretical pattern for CRYSMEB calculated from its atomic coordinates (blue), CRYSMEB (green) and the adduct 3 (pink).

CRYSMEB is a quite unique derivative of $\beta-C D$ considering that, although it is formed by a series of molecules with different number and position of methylation sites averaging at four in a narrow Gaussian distribution, it is also able to self organise in the solid-state to form single crystals. The crystal structure of this host was fully described by Harata from X-ray diffraction data. ${ }^{25}$ The geometry and packing of the CRYSMEB skeletons were identified, whilst the position of the methyl substituents was only statistically allocated over several occupation sites. In this structure, the CD molecules stack along the $a$ crystallographic axis in antiparallel zig-zag columns of tilted units, as depicted in Scheme 1.

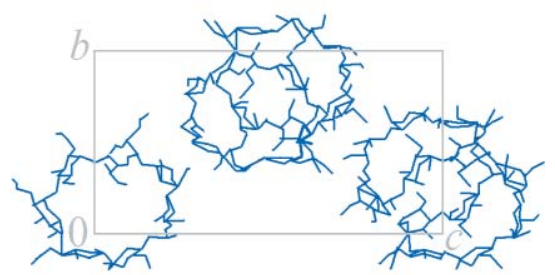

Scheme 1 Stacking of CD units in the structure of CRYSMEB as viewed along the $b$ axis, represented pictorially at the left, and on a top view along the $a$ axis, on the right. 
Lacking references in the literature concerning powder diffraction studies of this cyclodextrin, we have used the atomic coordinates of CRYSMEB determined by Harata to generate (using the software Mercury 2.2) ${ }^{26}$ a theoretical powder pattern used as model for the description of plain CRYSMEB and CRYSMEB·Ru([9]aneS 3 )(gly)Cl (5) samples (Fig. 1). Interestingly, both the bulk CRYSMEB provided from the manufacturer and the adduct 5 present overall envelopes of diffraction matching that calculated from the crystal structure, allowing to postulate that, in these compounds, CD units pack in a similar way as that found on CRYSMEB single crystals.

Thermogravimetric analysis is also a useful tool for the recognition of inclusion complex formation. Fig. 2 shows the thermograms for the guest $\mathbf{1}$, the inclusion compounds $\mathbf{2}-\mathbf{5}$ and the 1:1 physical mixtures of each cyclodextrin with the guest $\mathbf{1}$. Compound $\beta$-CD. $\mathrm{Ru}\left([9] \mathrm{aneS}_{3}\right)($ gly)Cl (2), exhibits a weight loss of $5.9 \%$ from room temperature up to about $100{ }^{\circ} \mathrm{C}$ (see Fig. $2 \mathrm{a}$ ), assigned to the removal of water molecules located in the $\beta-C D$ cavities, and also in the interstices between the macrocycles. After the dehydration step, the TG trace exhibits insignificant mass loss up to $210{ }^{\circ} \mathrm{C}$, when the host molecules in the inclusion
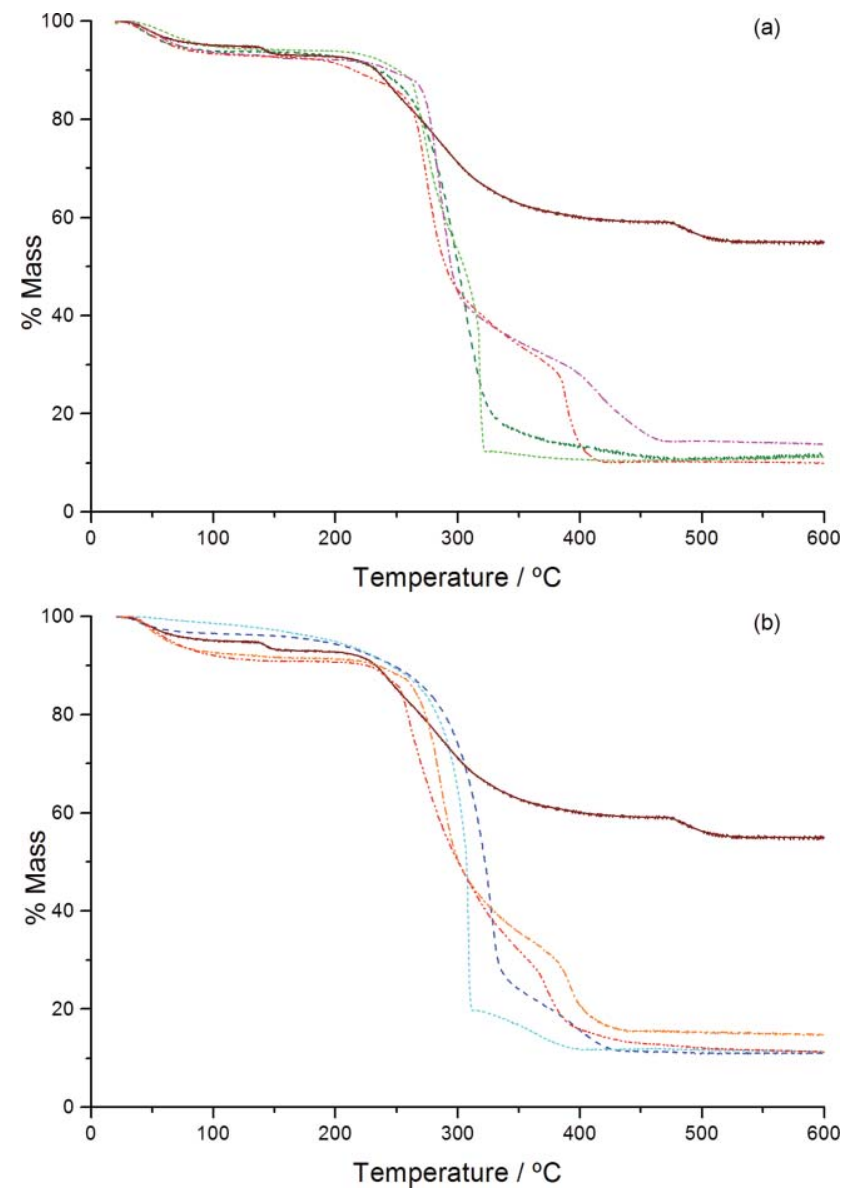

Fig. 2 TG traces for: a) the guest $\mathbf{1}\left({ }_{-}\right.$), a 1:1 physical mixture of $\mathbf{1}$ and $\beta-\mathrm{CD}(-=-)$, the inclusion compound $2(---)$, a 1:1 physical mixture of 1 and $\operatorname{HP} \beta C D(-=-)$, and the inclusion compound $3(-=--)$; b) the guest $\mathbf{1}$ (ـ), a 1:1 physical mixture of $\mathbf{1}$ and TRIMEB $\left(-=-{ }_{-}\right.$), inclusion compound $\mathbf{4}(--)$, a 1:1 physical mixture of $\mathbf{1}$ and CRYSMEB $(-=-)$, and the inclusion compound 5 ( $-=--)$. compound 2 start to decompose. Plain $\beta-\mathrm{CD}$ hydrate starts to decompose at around $270{ }^{\circ} \mathrm{C}$, so the early ring decomposition can be attributed to the promoting effects of ruthenium on the decomposition of $\beta$-cyclodextrin, and is further evidence for the existence of a significant host-guest interaction in the inclusion compound. ${ }^{27}$ At $440{ }^{\circ} \mathrm{C}$, compound 2 exhibits a residual mass rounding $11 \%$, which tallies well with a $1: 1$ stoichiometry as it is similar to that found for the corresponding physical mixture (mix).

The inclusion compound HP $\beta C D \cdot R u\left([9] \mathrm{aneS}_{3}\right)(\mathrm{gly}) \mathrm{Cl}$ (3) features a small step from room temperature to around $80{ }^{\circ} \mathrm{C}$ (see Fig. 2a) ascribed to dehydration (6.1\%). Host decomposition on this inclusion compound, as found for the one with native $\beta-C D$, also starts at lower temperature $\left(\mathrm{ca} .250^{\circ} \mathrm{C}\right)$ than the $\operatorname{mix}\left(260^{\circ} \mathrm{C}\right)$ and pure $\mathrm{HP} \beta \mathrm{CD}$, which starts to decompose around $290^{\circ} \mathrm{C}$ (not shown).

TRIMEB $\cdot \mathrm{Ru}\left([9] \mathrm{aneS}_{3}\right)(\mathrm{gly}) \mathrm{Cl}(\mathbf{4})$ has an inverse behaviour, as shown in Fig. 2b. While pure TRIMEB starts to melt and decompose at about $175^{\circ} \mathrm{C}$, compound $\mathbf{4}$ starts to decompose at around $265^{\circ} \mathrm{C}$, and similar results were observed in a $1: 1$ physical mixture of the two components prepared by mechanical grinding. We also note that the residual masses at $550{ }^{\circ} \mathrm{C}$ are similar and of about $7 \%$, thus further supporting the 1:1 host-to-guest stoichiometry in the inclusion compound $\mathbf{4}$ determined by microanalysis. The higher thermal stability of both TRIMEB $\cdot \mathrm{Ru}\left([9] \mathrm{aneS}_{3}\right)(\mathrm{gly}) \mathrm{Cl}(4)$ and its corresponding mix are an unusual feature, only observed when TRIMEB (rather than native $\beta$-CD) is used as host, and seems to occur only with very specific guest types. We have previously registered this thermal decomposition profile for TRIMEB encapsulated metallocenes $\left(\mathrm{Cp}_{2} \mathrm{MoCl}_{2}{ }^{11}\right.$ and $\left.\mathrm{Cp}_{2} \mathrm{NbCl}_{2}{ }^{28}\right)$ and, in a more recent study, obtained similar results for supramolecular TRIMEB adducts with other Ru([9]aneS $\left.{ }_{3}\right)$ guests. ${ }^{13,23}$

The inclusion compound of $\mathbf{1}$ with the other methylated host, CRYSMEB, depicts a thermal decomposition profile more similar to those of native $\beta$-CD adducts. This way, compound $\mathbf{5}$ starts to decompose at around $270{ }^{\circ} \mathrm{C}$ and its mix at $285{ }^{\circ} \mathrm{C}$, whilst pure CRYSMEB (not shown) presents an onset of thermal degradation around $300{ }^{\circ} \mathrm{C}$.

The ${ }^{13} \mathrm{C}\left\{{ }^{1} \mathrm{H}\right\} \mathrm{CP} / \mathrm{MAS}$ NMR spectra of the complex 1 , the hosts $\beta-C D$ and $H P \beta C D$ and their corresponding inclusion compounds, $\mathbf{2}$ and 3, are presented in Fig. 3. The complex $\mathbf{1}$ features broad carbon signals, centred at $184.5 \mathrm{ppm}$ for the carbonyl and at 45.3, 36.2 and $29.3 \mathrm{ppm}$ for the [9] $\mathrm{aneS}_{3}$ carbon atoms; the resonance for the $\mathrm{CH}_{2} \mathrm{NH}_{2}$ carbon (C2), expected around $40 \mathrm{ppm}$, is not observed, most likely due to overlapping with the macrocycle signals. The broad and poorly resolved resonances observed for 1 are coherent with its amorphous phase observed by XRD, and differ significantly from those found in previous work for the anhydrous form of its synthetic precursor, $\mathrm{Ru}\left([9] \mathrm{aneS} \mathrm{S}_{3}\right) \mathrm{dmsoCl}_{2},{ }^{13}$ with multiple resonances due to different orientations and, therefore, environments on the crystalline lattice. The spectrum of plain $\beta$-CD hydrate exhibits multiple sharp resonances for each type of carbon atom, correlated with different torsion angles about the $\alpha(1 \rightarrow 4)$ linkages, ${ }^{29,30}$ and with the torsion angles describing the orientation of the hydroxyl groups. ${ }^{31}$ Signal multiplicity is reduced upon inclusion of $\mathbf{1}$ to form $\beta-\mathrm{CD} \cdot \mathrm{Ru}\left([9] \mathrm{aneS}_{3}\right)(\mathrm{gly}) \mathrm{Cl}(\mathbf{2})$, thus suggesting the ring adopts a more symmetric conformation to better accommodate the guest. Resonances of the complex $\mathbf{1}$ are also observed in the spectrum of its $\beta-C D$ inclusion compound 


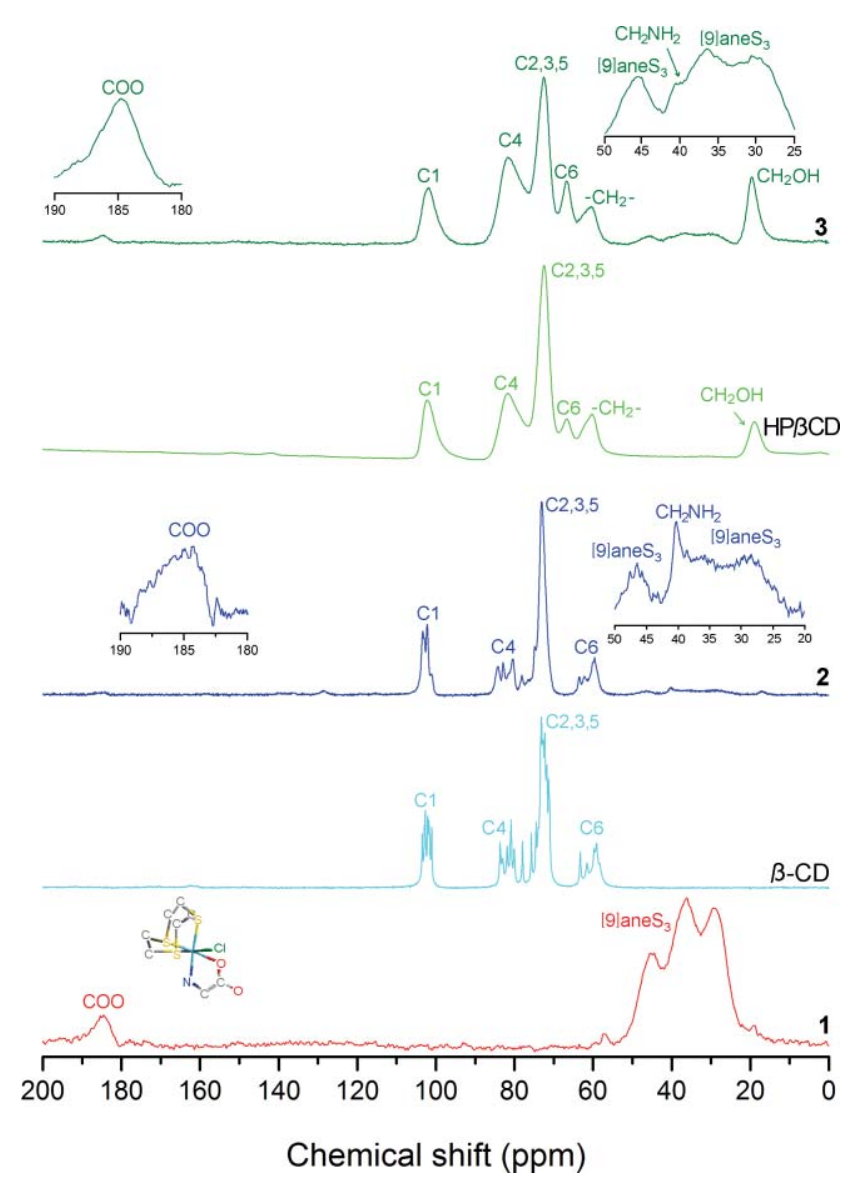

Fig. 3 Solid-state ${ }^{13} \mathrm{C}\{1 \mathrm{H}\} \mathrm{CP} / \mathrm{MAS} N \mathrm{MR}$ spectra, from bottom to top, of $\mathrm{Ru}\left([9] \mathrm{aneS}_{3}\right)(\mathrm{gly}) \mathrm{Cl}(\mathbf{1}), \beta-\mathrm{CD}$, compound 2, HP $\beta \mathrm{CD}$ and compound 3. A schematics of the ligands of compound $\mathbf{1}$ is also presented above the corresponding spectrum ( $\mathrm{Ru}$ and $\mathrm{H}$ atoms omitted for clarity).

(2), with no relevant changes in the chemical shifts, but featuring an interesting reduction in the intensity of one resonance of the thiolated macrocycle, that allowed for the signal of the glycine C2 carbon to become visible, peaking at $40.5 \mathrm{ppm}$. This resonance is also observed in the spectrum of $\mathrm{HP} \beta \mathrm{CD} \cdot \mathrm{Ru}\left([9] \mathrm{aneS} \mathrm{S}_{3}\right)(\mathrm{gly}) \mathrm{Cl}(\mathbf{3})$, although in a less evident way, consisting of a small shoulder on the [9] $\mathrm{aneS}_{3}$ region.

The spectra of $\mathbf{1}$ and its inclusion compounds with the methylated hosts are shown in Fig. 4, in comparison with those of pure TRIMEB and CRYSMEB. The permethylated cyclodextrin features, as its parent native $\beta-C D$, multiple resonances per each kind of carbon atom, ${ }^{32}$ that can be attributed either (i) to a collapsed conformation in the solid state by inversion of the conformation of one glucose unit to the ${ }^{1} \mathrm{C}_{4}$ conformation as observed for TRIMEB monohydrate, or (ii) to an overall asymmetry in the local environment of the glucose units due to self inclusion of two primary methoxyl groups from a neighbouring molecule, as found for the crystals of anhydrate TRIMEB. ${ }^{33}$ Note that an unambiguous assignment from powder diffraction data of the herein used TRIMEB to the monohydrate or anhydrate forms could not be made due to the absence of reference data collected at room temperature. The multiplicity of the carbon resonances is absent on the adduct $\mathbf{4}$, and only broad bands are observed, which is in agreement with the amorphous nature of
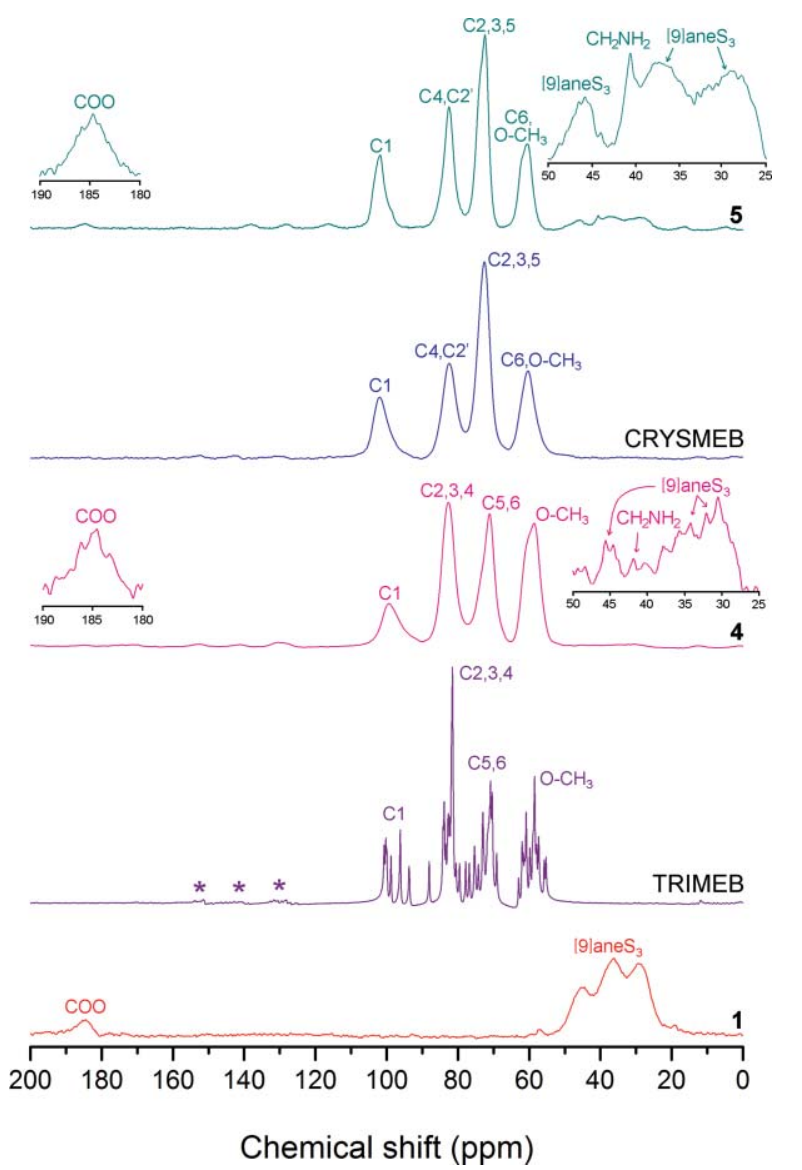

Fig. 4 Solid-state ${ }^{13} \mathrm{C}\{1 \mathrm{H}\} \mathrm{CP} / \mathrm{MAS}$ NMR spectra, from bottom to top, of $\mathrm{Ru}\left([9] \mathrm{aneS}_{3}\right)(\mathrm{gly}) \mathrm{Cl}(\mathbf{1})$, TRIMEB, compound 4, CRYSMEB and compound 5. Spinning sidebands denoted by asterisks.

the sample. The CRYSMEB ${ }^{13} \mathrm{C}\left\{{ }^{1} \mathrm{H}\right\} \mathrm{CP} / \mathrm{MAS}$ NMR spectrum presents broad resonances, as the expected result of the different methyl substituents positions. This way, the observed signals are a superposition of resonances arising from signals of carbons bearing unsubstituted hydroxyls and those of functionalised carbons of the 2, 3 and 6 positions. ${ }^{13} \mathrm{C}$ solution studies on CRYSMEB showed that methylation exherts little or no influence on the chemical shifts of carbons 4,5 and 6 , whilst shifts on carbons 1 and 3 are small, $(1-2 \mathrm{ppm})^{34}$ and therefore remain under the broad signals observed on the solid-state spectrum for the non-functionalised carbons. The strongest shift occurs for the $O$-methylated C2 (herein denoted as $\mathrm{C}^{\prime}$ '), from 71.8 to $81.3 \mathrm{ppm}$ in solution studies, ${ }^{34}$ that therefore in the solid-state spectrum is located under the broad signal of the $\mathrm{C} 4$ carbons, with a maximum at $82.5 \mathrm{ppm}$. CRYSMEB resonances suffer little or no change upon the formation of CRYSMEB·Ru([9]aneS $\left.\mathrm{A}_{3}\right)(\mathrm{gly}) \mathrm{Cl}(\mathbf{5})$, and the only noticeable change is observed on the guest resonances that exhibit the $\mathrm{CH}_{2} \mathrm{NH}_{2}$ carbon signal rising well above the broad envelope of the [9] $\mathrm{aneS}_{3}$ carbons. It is interesting to note that cyclodextrin inclusion has resulted, in general, in the enhancement of the $\mathrm{CH}_{2} \mathrm{NH}_{2}$ signal. A possible explanation is that cyclodextrins are docking onto the glycinate, involving it into the proton-rich environment of their cavities. Further evidence on this proposed inclusion geometry are the shifts observed for the COO stretching band by FT-IR, as discussed below. 
Table 1 Selected FTIR bands for the pure complex 1 and its different cyclodextrin adducts $\mathbf{2}-\mathbf{5}$

Observed frequency $\left(\mathrm{cm}^{-1}\right)$

\begin{tabular}{|c|c|c|c|c|c|}
\hline 1 & 2 & 3 & 4 & 5 & Approximate description \\
\hline 1400 & 1409 & 1409 & 1405 & 1407 & $\delta \mathrm{C}-\mathrm{H}\left([9] \operatorname{aneS}_{3}\right)^{b}$ \\
\hline 1448 & 1449 & $a$ & & & $\delta \mathrm{C}-\mathrm{H}\left([9] \mathrm{aneS}_{3}\right)^{b}$ \\
\hline 1613 & 1617 & 1624 & 1637 & 1614 & $v \mathrm{COO}_{\mathrm{as}}$ (glycinate) \\
\hline
\end{tabular}

${ }^{a}$ Not visible due to overlapping with host vibrations. ${ }^{b}$ By comparison with vibrational assignments for the precursor $\mathrm{Ru}[9] \mathrm{aneS}_{3}(\mathrm{DMSO}) \mathrm{Cl}_{2}$.

The FTIR spectra of the compounds allowed the confirmation of the structural integrity of the cyclodextrin hosts, of which the typical vibrational bands are mostly unaffected, and also the observation of some of the guest modes. The mode suffering the most evident effects of cyclodextrin inclusion is the $\mathrm{COO}$ anti-symmetric stretch, appearing blueshifted in all adducts, most likely due to the transition of this oscillator into the apolar host cavities. This feature, along with the observation of the $\mathrm{CH}_{2} \mathrm{NH}_{2}$ signal in the NMR spectra (that is not visible on the spectrum of pure 1), strongly supports inclusion geometries involving glycinate docking.

The inhibitory effect of the complex $\mathbf{1}$ and its cyclodextrin adducts $2-5$ against human bone cancer was evaluated towards the osteosarcoma cell line MG-63. The results, schematised in Fig. 5, show a slight ( $c a .15 \%)$ cell growth inhibition for complex 1 at $100 \mu \mathrm{M}$, after an incubation time of $72 \mathrm{~h}$. This mild, time-delayed action may not be suitable for the neoadjuvant chemotherapeutic, used for reducing tumour size (usually before surgical removal) but is adequate for adjuvant chemotherapy, after removal of the tumoural tissue. In bone cancer, the process usually involves replacing the removed bone with an implant. The present work is part of a project for developing implants coated with drugloaded materials to avoid intravenous chemotherapy. The complex 1, in light of its delayed onset of action, is ideal for this purpose, avoiding, for the first $48 \mathrm{~h}$, additional chemical-induced stress on the surrounding tissues that are recovering from surgery. Regarding the growth-inhibitory action of the inclusion compounds, no effect was observed towards the MG-63 cells at the times and concentrations tested. It is thus feasible that the release kinetics of the cyclodextrin vehicles is superior to $72 \mathrm{~h}$, which would account for the lack of activity observed; in fact, the free complex itself also has a delayed onset of action, with a statistically significant inhibition effect observed only after an incubation time of $72 \mathrm{~h}$. Time-dependent liberation studies for the inclusion compounds are thus required for a better understanding of their application potential on local chemotherapy on osteosarcoma.

The toxicity of plain native $\beta-C D$ and the derivatives $H P \beta C D$, TRIMEB and CRYSMEB on this cell line was also investigated by direct incubation with the MG-63 cell lines for a period up to $72 \mathrm{~h}$. No significant inhibition of growth could be observed, as depicted in Fig. 6, thus confirming that the plain hosts have no intrinsic damaging action on these cells.

\section{Conclusions and outlook}

A ruthenium(II) trithiacyclononane glycine complex was prepared in a simple, reproducible procedure, and successfully encapsulated into four cyclodextrin hosts to yield stable 1:1 inclusion compounds. Solid state characterisation revealed that $\mathrm{HP} \beta \mathrm{CD} \cdot \mathrm{Ru}\left([9] \mathrm{aneS}_{3}\right)(\mathrm{gly}) \mathrm{Cl}$ and TRIMEB$\cdot \mathrm{Ru}\left([9] \mathrm{aneS}_{3}\right)(\mathrm{gly}) \mathrm{Cl}$
1

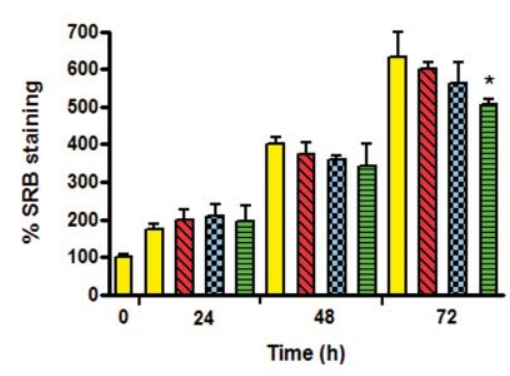

4

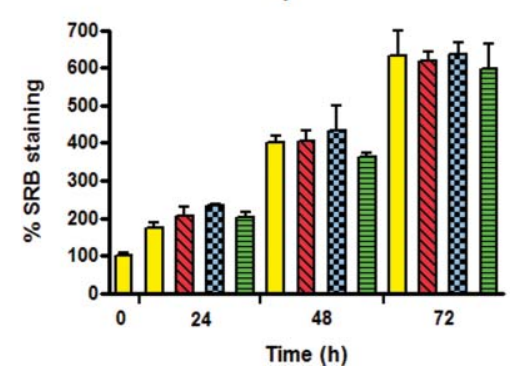

2

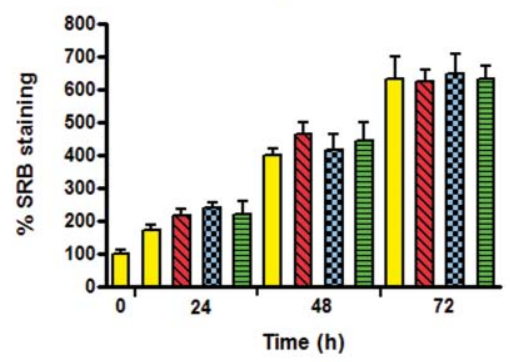

5

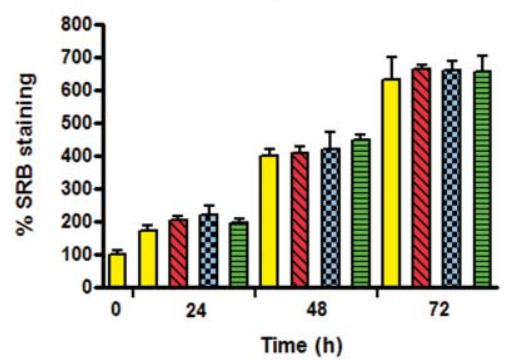

3
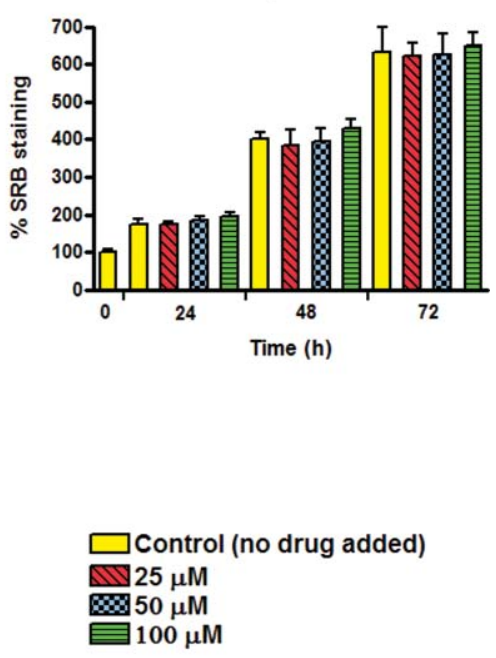

Fig. 5 Time- and dose-dependent effects of the compounds 1-5 on MG- 63 cell line proliferation. Cells were plated at a density of $1.75 \times 10^{4}$ cells $/ \mathrm{mL}$ on 24-well dishes and incubated with the drugs for periods of 24 to $72 \mathrm{~h}$. After $72 \mathrm{~h}$, cell density was evaluated using the sulforhodamine B (SRB) colorimetric assay. Results are expressed as a percentage of the control $(100 \%)$ and represent the average \pm mean standard deviation from the experiments carried out in triplicate. ${ }^{*} p<0.05$ by Tukey's post hoc test after one-way ANOVA. 
$\beta C D$

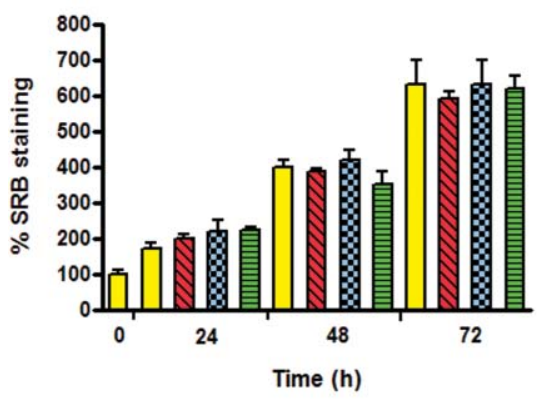

TRIMEB

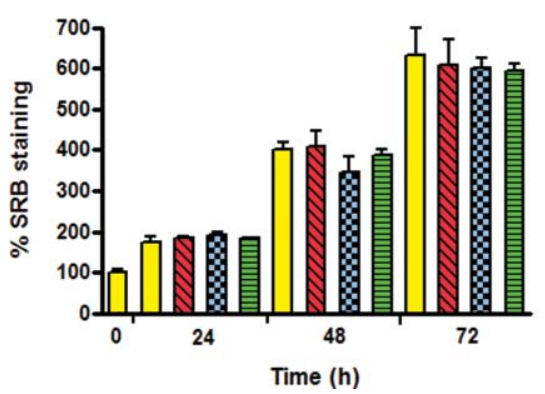

HPBCD

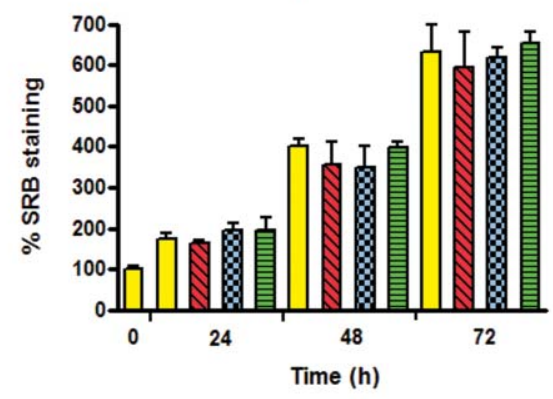

CRYSMEB

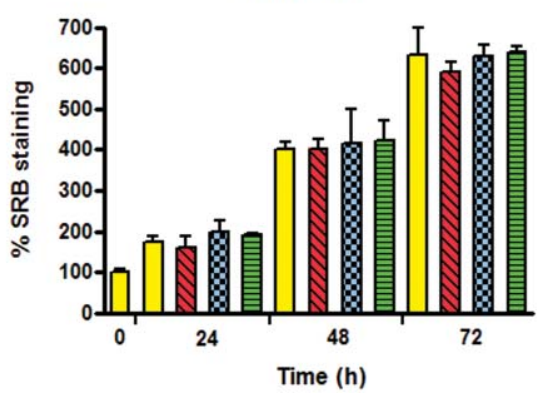

Fig. 6 Time- and dose-dependence of the cytotoxic effect of cyclodextrins $\beta C D$, HP $\beta C D$, TRIMEB and CRYSMEB towards the MG-63 cell line. (Details as in Fig. 5, see full description in the experimental section).

are amorphous, whilst $\beta$-CD $\cdot \mathrm{Ru}\left([9] \mathrm{aneS}_{3}\right)(\mathrm{gly}) \mathrm{Cl}$ and $\mathrm{CRYSMEB}$. $\mathrm{Ru}\left([9] \mathrm{aneS}_{3}\right)(\mathrm{gly}) \mathrm{Cl}$ present crystalline phases. The available experimental results further suggest that the interaction geometries generally involves insertion of the glycinate ligand into the host cavities.

The present work is part of a developmental study for local osteosarcoma chemotherapy, and considering the restrictions to intravenous use of $\beta-C D$ and TRIMEB associated with moderate haemolytic action, an assessment of the toxicological safety of cyclodextrins on osteosarcoma was carried out by evaluating the antiproliferative effect of $\beta-C D, H P \beta C D$, TRIMEB and CRYSMEB on MG-63 cells. None of these hosts presented intrinsic toxicity under the conditions tested, which constitutes a positive result for future application developments.

Antitumoural activity of complex $\mathbf{1}$ against the osteosarcoma MG-63 line showed an onset of activity only after $72 \mathrm{~h}$ of incubation, thus making it only suitable for niche applications such as incorporation into a bone implant as a local adjuvant chemotherapeutic agent. The cyclodextrin inclusion compounds 2-5, however, showed no action up to $72 \mathrm{~h}$. Although additional characterisation work, testing longer incubation times and evaluating the kinetics of release of $\mathbf{1}$ from the inclusion compounds in the cellular media, will be required to fully understand these results, it seems likely that the protective effects of cyclodextrins play an important role.

Future studies will be dedicated to the optimisation of the ruthenium drugs. The obvious approach will be to examine complexes with different amino acids with an important role on the physiology of bone, since some osteosarcoma cell lines are known to present osteoblast-like growth mechanisms. ${ }^{18}$

\section{Experimental}

\section{General considerations}

$\beta$-CD and CRYSMEB were kindly donated by laboratoires La Roquette (France), heptakis-2,3,6-tri- $O$-methyl- $\beta$ $\mathrm{CD}$ was obtained from Fluka and (2-hydroxy)-propyl- $\beta-\mathrm{CD}$ was from Cyclolab (Hungary). The precursor for 1, complex $\mathrm{Ru}\left([9] \mathrm{aneS} \mathrm{S}_{3}\right) \mathrm{dmsoCl}_{2}$, was synthesised using literature procedures. ${ }^{13}$ All air-sensitive operations were carried out using standard Schlenk techniques under argon.

Culture media (MEM) for the cytotoxicity experiments, antibiotics (penicillin-streptomycin 100x solution), fetal bovine serum (FBS), sulforhodamine B (SRB), trypsin and inorganic salts and acids (of analytical grade) were purchased from SigmaAldrich Chemical Co. The human osteosarcoma cell line (MG-63) was kindly provided by the Associate Laboratory IBMC-INEB, Portugal.

Microanalyses for $\mathrm{CHN}$ were performed at the University of Cambridge, and Ru was determined by ICP-OES at the Central Laboratory for Analysis, University of Aveiro (by L. Carvalho). TGA studies were carried out using a Shimadzu TGA-50 system at a heating rate of $5{ }^{\circ} \mathrm{C} \mathrm{min}{ }^{-1}$ under an air flow of $20 \mathrm{~mL} \mathrm{~min}^{-1}$. Laboratory powder XRD data were collected at ambient temperature on an X'Pert MPD Philips diffractometer $\left(\mathrm{CuK}_{\alpha}\right.$ X-radiation) with a curved graphite monochromator. Infrared spectra were recorded on a Unican Mattson Mod 7000 FTIR spectrophotometer. ${ }^{13} \mathrm{C}\left\{{ }^{1} \mathrm{H}\right\} \mathrm{CP} / \mathrm{MAS}$ NMR spectra were recorded at $125.72 \mathrm{MHz}$ on a $(11.7 \mathrm{~T})$ Bruker Avance 500 spectrometer, with an optimised $\pi / 2$ pulse for ${ }^{1} \mathrm{H}$ of $4.5 \mu \mathrm{s}$, 
$2 \mathrm{~ms}$ contact time, a spinning rate of $7 \mathrm{kHz}$ and $12 \mathrm{~s}$ recycle delays. Chemical shifts are quoted in parts per million from tetramethylsilane.

\section{Synthesis of $\mathrm{Ru}\left(\left[9 \mid \mathrm{aneS}_{3}\right)(\mathrm{gly}) \mathrm{Cl} 1\right.$}

To the complex $\mathrm{Ru}\left([9] \mathrm{aneS}_{3}\right)\left(\mathrm{dmso} \mathrm{Cl}_{2}(300 \mathrm{mg}, 0.70 \mathrm{mmol})\right.$ were added glycine $(62.5 \mathrm{mg}, 0.83 \mathrm{mmol})$ and sodium bicarbonate (87 $\mathrm{mg}, 1.04 \mathrm{mmol})$ in deaerated absolute ethanol $(66 \mathrm{~mL})$ with constant stirring. The resulting suspension was refluxed for 24 hours at $90{ }^{\circ} \mathrm{C}$, under an argon atmosphere. During reflux, the solution turned from colourless to brown. After cooling at room temperature, a white solid precipitated and the solution was decanted. To the decanted solution hexane $(28 \mathrm{~mL})$ was added and it was left in the refrigerator for one night. The solution was decanted, washed with hexane $(10 \mathrm{~mL})$ and evaporated to dryness to obtain a dark brown solid (240 mg, 80\% yield). Anal. Calcd for $\left(\mathrm{C}_{8} \mathrm{H}_{16} \mathrm{ClNO}_{2} \mathrm{RuS}_{3}\right) \cdot 2 \mathrm{H}_{2} \mathrm{O}$ (427.0): C, 22.50; H, 4.72; N, 3.28; $\mathrm{Ru}, 23.67$. Found: C, 22.87; H, 4.74; N, 2.96; Ru, 22.34\%. FTIR $\left(\mathrm{KBr}, \mathrm{cm}^{-1}\right): \tilde{v}=3425 \mathrm{vs}, 2964 \mathrm{~m}, 2924 \mathrm{~m}, 2851 \mathrm{w}, 1787 \mathrm{w}, 1613 \mathrm{vs}$, $1487 \mathrm{vw}, 1472 \mathrm{vw}, 1448 \mathrm{w}, 1400 \mathrm{~s}, 1383 \mathrm{~s}, 1337 \mathrm{sh}, 1320 \mathrm{sh}, 1300 \mathrm{vw}$, 1260 w, 1233 vw, 1163 w, 1129 w, 1075 w, 1052 vw, 1037 w, 1022 w, 944 vw, 911 w, 890 vw, 845 w, 823 w, 794 vw, 777 m, 722 w, 717 w, 709 w, $690 \mathrm{sh}, 615 \mathrm{sh}, 584 \mathrm{sh}, 566 \mathrm{sh}, 535 \mathrm{sh}, 491 \mathrm{vw}, 427 \mathrm{~m}$, 409 vw, 399 vw, 394 vw, 374 sh, 371 sh, 366 sh, 359 sh, 352 vw, 339 sh, 335 sh, 331 w, 314 w, 303 w. ${ }^{13} \mathrm{C}\left\{{ }^{1} \mathrm{H}\right\} \mathrm{CP} / \mathrm{MAS}$ NMR $\delta=$ 184.5 (COO), 45.3, 36.2, 29.3 ([9]aneS 3 ) ppm.

\section{Preparation of $\beta-C D \cdot R u\left([9] \mathrm{aneS}_{3}\right)($ gly $) \mathrm{Cl} 2$}

A solution of $\beta-C D(59 \mathrm{mg}, 0.045 \mathrm{mmol})$ in water $(1.5 \mathrm{~mL})$ was treated with another of $1(19 \mathrm{mg}, 0.045 \mathrm{mmol})$ in ethanol $(0.5 \mathrm{~mL})$. The resulting mixture was stirred at $45^{\circ}$ for one hour and then immediately frozen. Solvent removal by freeze-drying allowed the isolation of a dark brown solid. Anal. Calcd. for $\left(\mathrm{C}_{42} \mathrm{H}_{70} \mathrm{O}_{35}\right) \cdot\left(\mathrm{C}_{8} \mathrm{H}_{16} \mathrm{ClNO}_{2} \mathrm{RuS}_{3}\right) \cdot 7 \mathrm{H}_{2} \mathrm{O}$ (1652.0): C, 36.35; H, 6.10; N, 0.85; Ru, 6.12. Found: C, 35.84; H, 5.65; N, 0.67; Ru, 5.400\%. TGA up to $100{ }^{\circ} \mathrm{C}$ revealed a mass loss of $5.9 \%$ (calc. for $6 \mathrm{H}_{2} \mathrm{O}$ : $6.6 \%)$. FTIR $\left(\mathrm{KBr}, \mathrm{cm}^{-1}\right): \tilde{v}=3385 \mathrm{~s}, 2926 \mathrm{~m}, 2854 \mathrm{sh}, 1617 \mathrm{~m}$, $1449 \mathrm{sh}, 1409 \mathrm{~m}, 1384 \mathrm{~m}, 1370 \mathrm{~m}, 1334 \mathrm{~m}, 1300 \mathrm{~m}, 1261 \mathrm{w}, 1245 \mathrm{w}$, 1202 w, 1155 s, 1097 sh, 1079 s, 1054 vs, 1029 vs, 1004 s, 946 m, 937 sh, 912 w, 889 vw, 859 w, 850 w, 845 w, 822 w, 802 w, 792 w, $774 \mathrm{sh}, 756 \mathrm{~m}, 706 \mathrm{~m}, 668 \mathrm{~m}, 609 \mathrm{~m}, 578 \mathrm{~m}, 530 \mathrm{~m}, 480 \mathrm{~m}, 360 \mathrm{w}$, 343 w, 334 w, 324 w, 312 w, 303 w. ${ }^{13} \mathrm{C}\left\{{ }^{1} \mathrm{H}\right\}$ CP/MAS NMR: $\delta=184.9$ (guest COO), 103.3, 102.9, 102.2, 101.1 ( $\beta$-CD, C1), 84.2, 82.9, 80.4, 78.1 ( $\beta-\mathrm{CD}, \mathrm{C} 4), 74.9,73.1$ ( $\beta-\mathrm{CD}, \mathrm{C} 2,3,5), 63.6$, 62.3, 59.6 ( $\beta$-CD, C6), 46.5 (guest [9] ane $_{3}$ ), 40.2 (shoulder, guest $\mathrm{CH}_{2} \mathrm{NH}_{2}$ ), 35.3, 28.8 ppm (guest [9]aneS ${ }_{3}$ ).

\section{Preparation of HPßCD.Ru([9]aneS 3$)($ gly $)$ Cl 3}

A solution of HPßCD (196 mg, $0.14 \mathrm{mmol})$ in water $(25 \mathrm{~mL})$ was treated stepwise with solid $1(60 \mathrm{mg}, 0.14 \mathrm{mmol})$. The resulting mixture was stirred at $70{ }^{\circ} \mathrm{C}$ for one hour and subsequently freeze-dried to remove the solvent resulting in the isolation of a voluminous pale brown solid. Anal. Calcd for $\left(\mathrm{C}_{51} \mathrm{H}_{88} \mathrm{O}_{38}\right) \cdot\left(\mathrm{C}_{8} \mathrm{H}_{16} \mathrm{ClNO}_{2} \mathrm{RuS}_{3}\right) \cdot 2 \mathrm{H}_{2} \mathrm{O}$ (1736.2): C, 40.81; H, 6.27; N, 0.81; Ru, 5.82 Found: C, 41.19; H, 6.46; N, 0.85; Ru, 4.22\%. TGA up to $80{ }^{\circ} \mathrm{C}$ revealed a mass loss of $6.1 \%$ (calc. for $6 \mathrm{H}_{2} \mathrm{O}$ : $5.9 \%$ ). FTIR $\left(\mathrm{KBr}, \mathrm{cm}^{-1}\right): \tilde{v}=3405 \mathrm{vs}, 2971 \mathrm{~m}, 2928 \mathrm{~m}, 1624 \mathrm{~m}$,
$1456 \mathrm{~m}, 1409 \mathrm{~m}, 1380 \mathrm{~m}, 1334 \mathrm{~m}, 1299 \mathrm{~m}, 1241 \mathrm{w}, 1203 \mathrm{w}$, 1156 s, 1124 sh, 1107 sh, 1082 s, 1034 s, 949 w, 853 w, 822 w, $756 \mathrm{w}, 706 \mathrm{~m}, 662 \mathrm{~m}, 608 \mathrm{~m}, 581 \mathrm{~m}, 473 \mathrm{w}, 420 \mathrm{w}, 327 \mathrm{w}, 323 \mathrm{sh}$, 313 w, 306 w. ${ }^{13} \mathrm{C}\left\{{ }^{1} \mathrm{H}\right\} \mathrm{CP} / \mathrm{MAS}$ NMR: $\delta=184.5$ (guest COO),

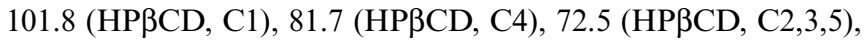
66.7 ( $\mathrm{HP} \beta C D,-\mathrm{OCH}_{2} \mathrm{CH}(\mathrm{OH}) \mathrm{CH}_{3}$ ), 60.5 (HPßCD, C6), 45.4 (guest [9] aneS ${ }_{3}$ ), 40.3 (guest $\mathrm{CH}_{2} \mathrm{NH}_{2}$ ), 36.6, 30.1 (guest [9]aneS ( ), $^{2}$ $19.5 \mathrm{ppm}\left(\mathrm{HP} \beta \mathrm{CD},-\mathrm{OCH}_{2} \mathrm{CH}(\mathrm{OH}) \mathrm{CH}_{3}\right)$.

\section{Preparation of TRIMEB·Ru([9]aneS $\left.S_{3}\right) \mathrm{glyCl} 4$}

A solution of TRIMEB $(200 \mathrm{mg}, 0.14 \mathrm{mmol})$ in water $(5 \mathrm{~mL})$ was treated stepwise with solid 1 (60 $\mathrm{mg}, 0.14 \mathrm{mmol})$. The resulting mixture was stirred at room temperature for one hour and left to slowly evaporate the solvent for seven days; as no precipitate was formed, the remaining solvent was evaporated to dryness under vacuum to give a vitreous light brown solid. Anal. Calcd. for $\left(\mathrm{C}_{63} \mathrm{H}_{112} \mathrm{O}_{35}\right) \cdot\left(\mathrm{C}_{8} \mathrm{H}_{16} \mathrm{ClNO}_{2} \mathrm{RuS}_{3}\right) \cdot 4 \mathrm{H}_{2} \mathrm{O}$ (1892.5): $\mathrm{C}, 45.06 ; \mathrm{H}$, 7.24; N, 0.74; Ru, 5.34. Found: C, 45.45; H, 6.91; N, 0.49; Ru, $4.30 \%$. FTIR $\left(\mathrm{KBr}, \mathrm{cm}^{-1}\right): \tilde{v}=3462 \mathrm{~s}, 2980 \mathrm{~m}, 2930 \mathrm{~m}, 2836 \mathrm{~m}$, $1749 \mathrm{vw}, 1634 \mathrm{~m}, 1460 \mathrm{~m}, 1405 \mathrm{~m}, 1384 \mathrm{~m}, 1369 \mathrm{sh}, 1324 \mathrm{w}$, 1303 w, 1261 w, 1234 m, 1206 sh, 1193 m, 1159 s, 1141 s, 1105 vs, 1088 vs, 1070 vs, 1037 vs, 968 m, 951 m, 910 w, 856 w, 822 w, 755 w, 705 w, 596 sh, 576 sh, 553 m, 520 sh, 452 w, 426 sh, 339 w. ${ }^{13} \mathrm{C}\left\{{ }^{1} \mathrm{H}\right\} \mathrm{CP} / \mathrm{MAS}$ NMR: $\delta=184.8$ (guest COO), 99.4 (TRIMEB, C1), 82.7 (TRIMEB, C2,3,4), 71.1 (TRIMEB, C5,6), 58.6 ppm (TRIMEB, O- $\mathrm{CH}_{3}$ ), 45.4 (guest [9]aneS ${ }_{3}$ ), 40.4 (guest $\mathrm{CH}_{2} \mathrm{NH}_{2}$ ), 36.0, 30.4 ppm (guest [9]aneS ${ }_{3}$ ).

\section{Preparation of CRYSMEB· $\left[9 S_{3}\right]$ RuglyCl 5}

To a solution of CRYSMEB $(167 \mathrm{mg}, 0.14 \mathrm{mmol})$ in water $(10 \mathrm{~mL})$ was added 1. (60 mg, $0.14 \mathrm{mmol})$. The resulting mixture was stirred at $70{ }^{\circ} \mathrm{C}$ for one hour and then left in the refrigerator to evaporate slowly, yielding a microcrystalline pale brown solid. Anal. Calcd. for $\left(\mathrm{C}_{46} \mathrm{H}_{78} \mathrm{O}_{35}\right) \cdot\left(\mathrm{C}_{8} \mathrm{H}_{16} \mathrm{ClNO}_{2} \mathrm{RuS}_{3}\right) \cdot 10 \mathrm{H}_{2} \mathrm{O}$ (1762.2): $\mathrm{C}, 36.81 ; \mathrm{H}$, 6.52; N, 0.79; Ru, 5.74. Found: C, 36.30; H, 5.96; N, 0.71; Ru, $6.00 \%$. FTIR $\left(\mathrm{KBr}, \mathrm{cm}^{-1}\right): \tilde{v}=3390 \mathrm{~s}, 2930 \mathrm{~m}, 2839$ w, $2088 \mathrm{vw}$, $1616 \mathrm{~m}, 1452 \mathrm{~m}, 1407 \mathrm{~m}, 1386 \mathrm{~m}, 1369 \mathrm{~m}, 1334 \mathrm{~m}, 1299 \mathrm{~m}$, 1259 sh, 1242 w, 1192 m, 1157 s, 1102 s, 1082 s, 1057 sh, 1032 vs, $1007 \mathrm{sh}, 962 \mathrm{~m}, 945 \mathrm{~m}, 912 \mathrm{sh}, 857 \mathrm{sh}, 843 \mathrm{sh}, 823 \mathrm{w}, 756 \mathrm{~m}$, $704 \mathrm{~m}, 667 \mathrm{~m}, 609 \mathrm{~m}, 575 \mathrm{~m}, 543 \mathrm{~m}, 499$ sh, 430 w, 366 w. ${ }^{13} \mathrm{C}\left\{{ }^{1} \mathrm{H}\right\}$ CP/MAS NMR: $\delta=184.7$ (guest COO), $101.9($ CRYSMEB, C1), 82.5 (CRYSMEB, C4 and C2'), 72.4 (CRYSMEB, C3,5 and C2), 60.5 (CRYSMEB, C6 and $\mathrm{O}-\mathrm{CH}_{3}$ ), 45.4 (guest [9] $\mathrm{aneS}_{3}$ ), 40.6 (guest $\mathrm{CH}_{2} \mathrm{NH}_{2}$ ), 37.0, 28.8 ppm (guest [9]aneS ). $^{\text {). }}$

\section{Preparation of solutions for biological assays}

All compounds studied were water soluble. Solutions were prepared at concentrations ranging from $2.5 \times 10^{-5}$ to $1.0 \times 10^{-4} \mathrm{M}$ in phosphate buffered saline (PBS) solution $\left(140.0 \times 10^{-3} \mathrm{M} \mathrm{NaCl}\right.$, $2.7 \times 10^{-3} \mathrm{M} \mathrm{KCl}, 1.5 \times 10^{-3} \mathrm{M} \mathrm{KH}_{2} \mathrm{PO}_{4}, 8.1 \times 10^{-3} \mathrm{M} \mathrm{Na}_{2} \mathrm{HPO}_{4}$ in Mili-Q water, $\mathrm{pH}$ 7.4) and sterilised by filtration. Sulforhodamine $\mathrm{B}$ was used as a $0.5 \%(\mathrm{w} / \mathrm{v})$ solution in $1 \%(\mathrm{v} / \mathrm{v})$ acetic acid.

\section{Cell culture}

Stock cultures of MG-63 cells were maintained at $37{ }^{\circ} \mathrm{C}$ in a humidified atmosphere under $5 \% \mathrm{CO}_{2}$. The cells (grown in 
monolayers) were kept in Eagle's Minimum Essential Medium (MEM), supplemented with $10 \%$ heat-inactivated fetal bovine serum, $1 \mathrm{mM}$ sodium pyruvate, non-essential amino acids and antibiotics (100 units of penicillin and $100 \mathrm{mg}$ of streptomycin). The cell line was subcultured twice a week. Cells were harvested upon addition of trypsin/EDTA ( $0.05 \%$ trypsin/EDTA solution).

\section{Toxicity and cell growth inhibition evaluation}

Cytotoxicity and cell density evaluation following drug exposurefor drug concentrations of 25,50 and $100 \mu \mathrm{M}$ - were assessed using the sulforhodamine B (SRB) colorimetric assay. The SRB assay is used for cell density determination and drug-induced cytotoxicity, based on the measurement of cellular protein content obtained from the ability of the protein dye sulforhodamine B to bind to protein basic amino acid residues of fixed cells. ${ }^{35}$ Cells were plated at a density of $1.75 \times 10^{4}$ cells $/ \mathrm{mL}$ on 24 -well dishes. Twenty four hours after seeding, drug solutions were added to the medium and the cultures were incubated at $37^{\circ} \mathrm{C}$. After $72 \mathrm{~h}$, cells were fixed with ice-cold $1 \%$ acetic acid in methanol for $2 \mathrm{~h}$. Then, sulforhodamine $\mathrm{B}$ was added to each well and allowed to stain for 1 hour at $37{ }^{\circ} \mathrm{C}$. The sulforhodamine B solution was removed by washing the dishes with $1 \%$ acetic acid to eliminate the unbound dye and the dishes were dried under air. The bound sulforhodamine $B$ was solubilised through the addition of a $10 \mathrm{mM}$ Tris base $(\mathrm{pH}=10)$ solution. $200 \mu \mathrm{L}$ of each well were transferred to a 96-well dish and measurements were carried out in a 96-well microplate reader at a working wavelength of $540 \mathrm{~nm}$.

\section{Statistical analysis of growth inhibition results}

All experiments were performed in triplicate. The results are expressed as mean values \pm SD (the corresponding error bars being displayed in the graphical plots). Statistical analysis was performed by ANOVA. Tukey's post hoc test was used for statistical comparison between the experimental data, $p$-values less than 0.05 having been considered as significant.

\section{Acknowledgements}

The present work was partly funded by FCT and FEDER (Project PDTC/SAU-BEB/66896/2006). We kindly thank the University of Cambridge for performing the $\mathrm{CNH}$ analysis.

\section{References}

1 A. M. Pizarro and P. J. Sadler, Biochimie, 2009, DOI: 10.1016/ j.biochi.2009.03.017.

2 (a) B. Rosenberg, L. VanCamp and T. Krigas, Nature, 1965, 205, 698 699; (b) B. Rosenberg, L. VanCamp, J. E. Trosko and V. H. Mansour, Nature, 1969, 222, 385-386.

3 (a) T. W. Hambley, Dalton Trans., 2007, 4929-4937; (b) I. Ott and R. Gust, Arch. Pharm., 2007, 340, 117-126.

4 (a) P. C. A. Bruijnincx and P. J. Sadler, Curr. Opin. Chem. Biol., 2008, 12, 197-206; (b) A. Alama, B. Tasso, F. Novelli and F. Sparatore, Drug Discovery Today, 2009, 14, 500-508.

5 B. Serli, E. Zangrando, T. Gianferrara, C. Scolaro, P. J. Dyson, A. Bergamo and E. Alessio, Eur. J. Inorg. Chem., 2005, 3423-3434.

6 I. Bratsos, S. Jedner, A. Bergamo, G. Sava, T. Gianferrara, E. Zangrando and E. Alessio, J. Inorg. Biochem., 2008, 102, 1120-1133.
7 T. M. Santos, J. Madureira, B. J. Goodfellow, M. G. B. Drew, J. P. de Jesus and V. Felix, Met.-Based Drugs, 2001, 8, 125-135.

8 (a) T. Loftsson and M. E. Brewster, J. Pharm. Sci., 1996, 85, 1017-1025; (b) R. A. Rajewski and V. J. Stella, J. Pharm. Sci., 1996, 85, 1142-1169.

9 (a) J. Szejtli, Chem. Rev., 1998, 98, 1743-1754; (b) E. Fenyvesi, L. Szente, N. R. Russel, M. McNamara, in Comprehensive Supramolecular Chemistry, Pergamon, Oxford, 1996, 3, 305-366.

10 (a) S. S. Braga, P. Ribeiro-Claro, M. Pillinger, I. S. Gonçalves, A. C. Fernandes, F. Pereira, C. C. Romão, P. B. Correia and J. J. C. TeixeiraDias, J. Inclusion Phenom. Mol. Recognit. Chem., 2003, 47, 47-52; (b) S. S. Braga, I. S. Gonçalves, E. Herdtweck and J. J. C. Teixeira-Dias, New J. Chem., 2003, 27, 597-601; (c) S. S. Braga, P. Ribeiro-Claro, M. Pillinger, I. S. Gonçalves, F. Pereira, A. C. Fernandes, C. C. Romão, P. B. Correia and J. J. C. Teixeira-Dias, Org. Biomol. Chem., 2003, 1, 873-878.

11 S. S. Braga, M. P. M. Marques, J. B. Sousa, M. Pillinger, J. J. C. TeixeiraDias and I. S. Gonçalves, J. Organomet. Chem., 2005, 690, 29052912.

12 C. C. L. Pereira, C. V. Diogo, A. Burgeiro, P. J. Oliveira, M. P. M. Marques, S. S. Braga, F. A. A. Paz, M. Pillinger and I. S. Gonçalves, Organometallics, 2008, 27, 4948-4956.

13 J. Marques, T. M. Braga, F. A. A. Paz, T. M. Santos, M. F. S. Lopes and S. S. Braga, BioMetals, 2009, 22, 541-556.

14 (a) A. Frodl, D. Herebian and W. S. Sheldrick, J. Chem. Soc., Dalton Trans., 2002, 3664-3673; (b) Y. Nakabayashi, Y. Watanabe, T. Nakao and O. Yamauchi, Inorg. Chim. Acta, 2004, 357, 2553-2560.

15 K. E. Sandman, P. Fuhrmann and S. J. Lippard, JBIC, J. Biol. Inorg. Chem., 1998, 3, 74-80.

16 P. K.-M. Siu, D.-L. Ma and C.-M. Che, Chem. Commun., 2005, $1025-$ 1027.

17 E. Hinoi, T. Takarada and Y. Yoneda, J. Pharmacol. Sci., 2004, 94, $215-220$.

18 J. G. Spangler, Med. Hypotheses, 2008, 70, 281-286.

19 C. F. Campana, D. F. Shepard and W. M. Litchman, Inorg. Chem., 1981, 20, 4039 .

20 K. Majumder, R. J. Butcher and S. Bhattacharya, Inorg. Chem., 2002, 41, 4605-4609.

21 M. T. Rosado, M. L. T. S. Duarte and R. Fausto, Vib. Spectrosc., 1998, 16, 35-54.

22 C. Djordjevic, N. Vuletic, B. A. Jacobs, M. Lee-Renslo and E. Sinn, Inorg. Chem., 1997, 36, 1798-1805.

23 J. Marques, L. Anjo, M. P. M. Marques, T. M. Santos, F. A. A. Paz and S. S. Braga, J. Organomet. Chem., 2008, 693, 3021-3028.

24 M. R. Caira, Rev. Roumaine Chim., 2001, 46, 371-386.

$25 \mathrm{~K}$. Harata, CSD code ref IQOZIX.

26 C. F. Macrae, I. J. Bruno, J. A. Chisholm, P. R. Edgington, P. McCabe, E. Pidcock, L. Rodriguez-Monge, R. Taylor, J. van de Streek and P. A. Wood, J. Appl. Crystallogr., 2008, 41, 466-470.

27 A. Harada, K. Saeki and S. Takahashi, Organometallics, 1989, 8, 730 733.

28 C. C. L. Pereira, M. Nolasco, S. S. Braga, F. A. Almeida Paz, P. RibeiroClaro, M. Pillinger and I. S. Gonçalves, Organometallics, 2007, 26, 4220-4228.

29 M. J. Gidley and S. M. Bociek, J. Am. Chem. Soc., 1988, 110, 3820 3829.

30 S. J. Heyes, N. J. Clayden and C. M. Dobson, Carbohydr. Res., 1992, 233, 1-14.

31 R. P. Veregin, C. A. Fyfe, R. H. Marchessault and M. G. Tayler, Carbohydr. Res., 1987, 160, 41-56.

32 (a) Ž. Petrovski, S. S. Braga, S. S. Rodrigues, C. C. L. Pereira, I. S. Gonçalves, M. Pillinger, C. Freire and C. C. Romão, New J. Chem., 2005, 29, 347-354; (b) Ž. Petrovski, S. S. Braga, A. M. Santos, S. S. Rodrigues, I. S. Gonçalves, M. Pillinger, F. E. Kühn and C. C. Romão, Inorg. Chim. Acta, 2005, 358, 981-988.

33 G. R. Brown, M. R. Caira, L. R. Nassimbeni and B. van Oudtshoorn, J. Inclusion Phenom. Mol. Recognit. Chem., 1996, 26, 281-294.

34 Y. Bakkour, PhD Thesis, Université des Sciences et Technologies de Lille 1, 2005.

35 P. Skehan, R. Storeng, D. Scudiero, A. Monks, J. McMahon, D. Vistica, J. T. Warren, H. Bokesch, S. Kenney and M. R. Boyd, J. Natl. Cancer Inst., 1990, 82, 1107-1112. 